\title{
USING THE BASIS OF PEDAGOGICAL SKILLS IN ORGANIZING THE EDUCATIONAL PROCESS
}

\author{
Suyunov O.J. \\ PhD., \\ Docent of Samarkand Institute of Economics and Service.
}

\begin{abstract}
The article discusses ways to effectively use the basics of pedagogical skills and the need to organize lessons based on problem-based learning to increase the effectiveness of the educational process in higher education.

Keywords: Knowledge, Situation, Situational Analysis, Profession, Problem Situation, Learning, Teaching, Teaching, Heuristic Learning, Modular Learning, Intelligence, Types of Teaching.
\end{abstract}

\section{INTRODUCTION}

The general pedagogical experience of modern, advanced teachers in the field of education - the ability and skill to assess the mastery of the educational process.

Evidence shows that speakers who teach with interest and enthusiasm have made great strides in motivating students to learn. Such research notes that effective teaching speakers are not only informative but also provide real knowledge to students. It is important to note that an effective and well-organized presentation is better than a copy of a PowerPoint presentation and cannot replace a presentation.

After the independence of our republic, in a very short period of time it was set the task of training mature specialists who will think innovatively and consciously fight for the development and progress of the republic. Deep knowledge alone is not enough to form a mature specialist and innovative thinker President of the Republic of Uzbekistan Sh. Mirziyoyev put it: "We don't need graduates, we need educated people." In this way, the President showed that it is not necessary to acquire a set of knowledge, but to acquire it and learn the secrets that will serve to master the secrets and skills of various professions.

Today, the basis of sustainable development of any state is innovative activity. History has shown that man, with his intellect, invented the first tools of labor, from the invention of algorithms and nanoparticles, modern innovative computers and other high technologies. has come a long way.

"Today, we are on the path of innovative development aimed at radically renewing all spheres of life of the state and society. This is not in vain, of course. Because who will win in today's fast-paced world? A state that relies on new ideas, new ideas wins. Innovation means the future. If we are to start building our great future today, we must start with innovative ideas, innovative approaches".

An important condition for increasing the effectiveness of the educational process in higher education depends on the introduction of innovations used in the education system of developed countries in the educational process of educational institutions of our country and the effective use of pedagogical skills in the organization of the educational process.

Analysis of the literature on the subject. Everyone has the ability to do something. According to some well-known psychologists (F. Gonobolin, N. Kuzmina), the following 6 skills are important for the pedagogical profession:

1. Ability to intervene;

2. Organization;

3. Self-control;

4. Be able to plan, estimate;

5. Strength, intelligence;

6. Creative approach to activity.

All of this can only be part of a pedagogical ability if it has an educational purpose and is approached from a humanitarian perspective.

Professor N.Azizkhodjaeva recommends the use of problematic situations for the effective use of the basics of pedagogical skills in the organization of the educational process. is the lack of previously acquired knowledge to obtain.These contradictions serve as a driving force for the acquisition of creative knowledge.

N. Azizkhodjaeva also expressed the following views on the solution of problematic issues in the educational process:

$>$ Students will not be able to find a solution to a problem, will not be able to answer a problem in a timely manner, and will have difficulty understanding a new topic;

$>$ Students are not able to apply their previous knowledge in new situations and situations;

$>$ There is a contradiction between their theoretical solution of the problem and their implementation of the chosen method.

Lack of knowledge between the results of students' practical assignments and their theoretical understanding can also lead to problematic situations. 
Pedagogical communication usually means that the teacher has clear pedagogical functions with the student during and after the lesson and creates a comfortable psychological environment, as well as for students with other types of psychologically optimal scientific activity and pedagogue. rta is understood as a form of oriented professional communication for the relationship (A.A. Leontev).

\section{LITERATURE REVIEW}

The following scholars have studied using the basics of pedagogical skills in the organization of the educational process in their literature Mirziyoyev Sh.M. [1], Ernazarov O.E. [2], Azizxodjaeva N.N. [3], Yuldashev J., Khasanov S. [4].

\section{RESEARCH METHODOLOGY}

The lack of development of the theory and methodology of pedagogical skills leads to the fact that each educator conducts creative research on his own: how to find a common language with students, with the pedagogical team? How can a realistic picture of student relationships be achieved in a short period of time? seeks answers to the following questions.

The answers to these questions are related to the formation of general pedagogical skills necessary for the work of every skilled educator. to be able to evaluate their activities correctly, as well as to be able to treat students in a humane manner. In Ibn Sina's "Event of Address", the teacher emphasizes that when choosing a teacher for a student, it is important to pay attention to him being a person who speaks the right words, is honest, clean, and loves the students. meant the quality of humanity.

\section{ANALYSIS AND RESULTS}

The personal aspirations and attitudes of the teacher are important components of pedagogical skills. His personal attitude is explained by the fact that he has a system of thoughts in an appropriate pattern, so that in many cases he can respond almost automatically. For example, to be polite to students, to have a high level of principled approach to the student's personality, to make sure that none of his students are bad, and not to be unreliable.

The types of seminars we reviewed consisted of a system of classes designed to prepare students for problem-based learning and to perform a number of pedagogical tasks.

Stimulating and shaping students' interest in learning is likely to increase their motivation to learn. The introductory part of the lecture is the most important issue, convincing the students that they should listen to the lecture.

Organizing a search for an answer to a problematic question has included a module of routine steps. They are:

- ask a problematic question;

- encourage students to think about how to answer and justify questions;

- organize a critical analysis of responses, identify their strengths and weaknesses;

- develop an agreed position - organize the comparison of answers in order to construct the most correct answer;

- move on to the next problematic question.

Problem-based learning creates a problematic situation under the guidance of a teacher, which involves the organization of the educational process that allows students to creatively acquire knowledge, skills and abilities and develop intellectual activity as a result of active independent work.

For many years, researchers in the field of education have been researching that in order for higher education to be effective, higher education must be taught in a specific area.

Ibn Sina's exemplary words about the teacher's persuasion in teaching and learning are valuable: "Every word must be confirmed by action and facial expressions, and must evoke emotion in the students." In addition to the method of persuasion, the method of persuasion is used in pedagogical influence. For many years, influence in the pedagogical process was unrecognized. Whether we like it or not, the elements of influence play an important role in our interactions in life. Through words, we instill in students a sense of alertness or fear, self-confidence or insecurity, boredom, confidence or doubt.

Persuasion must meet the following pedagogical requirements to be most effective in collaborative interactions:

- the content and form of persuasion should be appropriate to the level of development of the student (fairy tales, fantasy stories, etc. for younger students);

- take into account the individual characteristics of students in persuasion;

- persuasion is based on generalized, concrete bases, examples, audio materials in primary school;

- in persuasion, the teacher must have deep faith in what he or she is reporting, and so on.

The effect of persuasion on interaction is to:

- the strength of the interaction depends on the reputation of the persuasive and the content of the event (the more positive the student is to the teacher, the faster he believes in him);

- to take into account the individual mental state of the student in persuasion;

- in persuasion, the intellectual and emotional state of the persuader must correspond to the state of the believer. For example, when a student is overwhelmed with excitement, it is ineffective to influence him by pointing out his flaws in his behavior. 


\section{CONCLUSION/RECOMMENDATIONS}

An important condition for improving the efficiency of the educational process in higher education is the introduction of innovations used in the education system of developed countries in the educational process of educational institutions of our country and the organization of the educational process. effective use of the basics of pedagogical skills is important. The use of problem-based learning technology in education is a universal tool in the implementation of the educational process. This technology is only effective when students are prepared for situational problem-solving activities, problemsolving, and problem-solving. Thus, problem-based learning is a pedagogical technology of teaching, which synthesizes the creative processes of teacher and student in its content and structure. consists of the process of clarifying goals by moving to situations. Thus, the effective use of the basics of pedagogical skills and problem-based learning technologies in the organization of the educational process helps students to effectively master the knowledge systems and intellectual, practical activities, and the acquired new knowledge will help to solve future educational problems. It opens up opportunities to solve, teach independent research, gain and develop creative experience, analyze the tasks of the educational process, identify problem-based learning. In short, a new approach to the educational process, Only when creativity is applied and the process of pedagogical activity is methodologically and psychologically correct, the effectiveness of education rises to a new level, namely:

- the child's needs, inclinations, desires are met at the level of his abilities;

- increases the responsibility, accountability and duty of the student to the academic work;

- skills of independent acquisition of knowledge are formed;

- he has the confidence that he will enrich his knowledge for the rest of his life;

- develops the ability to think freely;

- creates an environment in which an individual can quickly find his place in society.

To do this, we need to move from the compelling call to "You need to know this" to instill in the reader an inner conviction and aspiration that "I need this and I am able to know it and apply it in my life".

\section{REFERENCES}

[1] Address of the President of the Republic of Uzbekistan Sh. Mirziyoyev to the Oliy Majlis. December 29, 2020. // www.uza.uz;

[2] Ernazarov O.E. Methods of Evaluating the Efficiency of Innovations in Industrial Enterprises. International Journal of Research - 2020. - Volume 07 - Issue 07. Available at https://journals.pen2print.org/index.php/ijr;

[3] Azizxodjaeva N.N. Pedagogical technology and pedagogical skills. - T., 2012;

[4] Yuldashev J., Khasanov S. "Pedagogical technology" - T .: TMI, 2014. 